\title{
Karate Program as an Extension Service: Impact and Challenges
}

\author{
Paulino V. Pioquinto \\ Dean, College of Criminology
}

\author{
Mauro Allan P. Amparado \\ Director, Community Awareness, Relations \& \\ Extension Services \\ http://orcid.org/0000-0002-2742-2508 \\ mapamparado@gmail.com
}

\section{University of Cebu Lapu-Lapu and Mandaue, Mandaue City, Cebu, Philippines}

\begin{abstract}
This study evaluated the Karate Program as an extension service to the youth of Village Looc and Village Opao, Mandaue City. Implemented by the College of Criminology, fifteen recipients were invited to join in the program to teach them self-defense. This descriptive quantitative study evaluated the performance of the recipients in three aspects: basic karate, basic kata, and basic kumite. The performance evaluation was conducted for 6 months. The study was conducted among fifteen enrollees of the University of Cebu Lapu-Lapu and Mandaue Karate Program. A five-point likert scale instrument was used to evaluate the performance of the recipients.

Based on the results of the Basic Karate Form, recipients were Very Good in 7 aspects. These includes close stance, natural stance, forward stance, lunge punch, reverse punch, downward block, and rising block. The basic kata and basic kumite techniques were rated as satisfactory. Overall, the basic karate form was rated as satisfactory.
\end{abstract}


Among the techniques of the basic karate form, the following had the lowest performance evaluation: knife hand block, round house kick, triple punch, side kick, and back stance.

In the basic kata techniques, the transitional movements, synchronization, and balance were among the techniques with the lowest performance evaluation. For basic kumite techniques, the vigorous application (2.8), awareness (2.8), good timing (2.8), and correct distance (2.8).

As an art to foster self-discipline and reliance, and one of the community extension programs of the college, the researcher concludes that there is a need to improve the skills performance of the recipients. This gap may be addressed by reinforcing lessons on basic techniques with the lowest performance evaluation. The researchers recommend the awarding of belts and conduct of tournaments to enhance competitiveness.

Keywords: Karate; Kata; Kumite; Performance Evaluation; Mandaue City, Cebu, Philippines

\section{Introduction}

Karate of all types is primarily a stand up or striking martial art that emerged on the island of Okinawa as a blend of native Okinawan fighting styles and Chinese fighting styles. The term karateka refers to a karate practitioner.

Karate is primarily a striking art that teaches practitioners to utilize punches, kicks, knees, elbows and open hand strikes to disable opponents. Beyond this, karate teaches practitioners to block strikes and breath properly. 
Most styles of karate also extend into throws and joint locks. Weapons are utilized in most styles as well. Interestingly, these weapons are often farm tools because they allowed Okinawans not to broadcast the fact that they were practicing to defend themselves during a time when weapons were forbidden. The basic goal of karate is self-defense. It teaches practitioners to block the strikes of opponents and then disable them quickly with pinpoint strikes. When takedowns are employed within the art, they tend to be used to set up finishing strikes.

In early times, natives to the Ryukyu Islands developed a fighting system that was simply referred to as 'te'. The largest island in the Ryukyu chain is Okinawa Island, which is generally considered the birthplace of karate. In 1372, trade relationships were established between the Ryukyu Islands and the Fujian Province of China, and this eventually spurred several Chinese families to move to Okinawa. These Chinese families began to share Chinese Kenpo, a blend of Chinese and Indian fighting styles, with the native Okinawans they encountered. Through this, traditional Okinawan fighting techniques began to change, even if many families simply developed their own styles of martial arts in isolation.

Three general styles emerged and were named after the areas where they developed: Shuri-te, Naha-te and Tomari-te. The differences between the three styles were small, as the cities of Shuri, Tomari and Naha were all very close to one another.

The fact that the invading Shimazu clan banned weapons in Okinawa in the 1400s spurred the development of not only martial arts and karate in Okinawa but also the use of inconspicuous farm tools as weapons. This is the reason why so many unusual weapons are used in karate today. 
As relations with China strengthened, the blend of the more traditional Okinawan fighting styles with those of Chinese Kenpo and the empty handed Chinese styles of Fujian White Crane, Five Ancestors, and Gangrou-quan, became more obvious. In addition, Southeast Asia influences were also brought into the fold, though perhaps to a lesser extent.

There are many different types of martial arts, and each has a ranking system. Most rankings go from beginner to experienced master. Rankings vary widely between the many arts. Belts and belt colors vary even more than rankings do. Belt colors will almost always be different from one karate school to another, and the same is true in different types of martial arts, and even some instructors will vary on the way they use their belts. Some martial arts don't even have belts, while others have only white and black belts. More commonly, however, karate schools carry a rainbow of colors to signify the advancement of their students from one level to the next. Instructors are also different in their behaviors.

White has always been the symbol of purity. This is quite suiting, as those who begin in the art of karate are innocent and unknowing to the work and discipline required of them to achieve mastery of the art. This is the beginning of a voyage from innocence to mastery, and this level introduces the first ideas of karate.

Once a student has a yellow belt, he/she has advanced from the introductory level. He has now transformed from a pure novice to developing a basic understanding in the art of karate. The yellow belt is representative of one's energy. In this mastery, the student has gained greater control over his body's energy.

Stability is the symbol of an orange belt. Karate practice includes basic postures, punches, blocks and kicks. The white, yellow, and orange belts are the basic principal building blocks, and 
all other methods learned in higher belts are built upon these basic skills.

When a student has achieved purple belt status, this student have advanced from the beginner level to the intermediate level. Students at this belt color should understand all standard blocks and strikes, while also knowing how to contort and move their body to achieve the desired block or strike.

Once the basic skills of the white, yellow, orange, and purple belts have been mastered, the student must learn to become more adaptable to given situations. The purpose of the blue belt is to reflect that the student has demonstrated fluidity and adaptability. With fluidity comes greater strength and confidence.

The green belt is the belt where students become humbled and dedicated as training becomes harder and more serious. With this transition comes a great flow of emotion and sensitivity.

When a student achieves his/her brown belt, this is the introduction to the advanced level of martial arts. This belt symbolizes that the student is experienced and knowledgeable in the art that they are studying.

Those who reach red belts are nearing at mastery. Students are required to be both practical and creative in their techniques. Confidence sets in as one's own personality is integrated with the many techniques they have already mastered.

A black belt is the summit of achievement in the martial arts. Many people work years to accomplish the mastery of a black belt. While the black belt is a symbol of great achievement, the belt itself is not the ultimate goal. The real reward is in the new selfawareness this belt represents. 
The College of Criminology anchored this study on two previous studies conducted by the university. The first study was conducted by Amparado, Camayra, Dorio \& Patindol. The researchers discovered that the community needs of Village Looc, Mandaue City, Cebu, Philippines were solid waste management, health education, literacy, livelihood, greening, livestock raising, and community participation programs (2017). On the second study, Amparado \& Colonia revealed that the community needs of Village Opao, Mandaue City, Cebu, Philippines includes literacy, livelihood, backyard gardening, backyard gardening, livestock raising, flooding, family planning, administration of tetanus toxoid, and community participation programs (2020).

Implemented as a community extension service, the College of Criminology evaluated the impact and the challenges of the Karate Program, the findings served as basis for program enhancements. 


\section{Related Studies}

A study in Finland determined the acute injury profile in each of six sports and compared the injury rates between the sports. The data was taken from the national sports injury insurance registry data from 1987 to 1991 . There were 54,186 injured persons were recorded in soccer, ice hockey, volleyball, basketball, judo, and karate. Injury rates were low in athletes aged under 15, while those aging 20-24 year old had the highest rates. Differences in injury rates between the sports were minor in this adult age group. Overall injury rates were higher in sports entailing more frequent and powerful body contact. Each sport had a specific injury profile. Fractures and dental injuries were most common in ice hockey and karate and least frequent in volleyball. Knee injuries were the most common cause of permanent disability. Based on the defined injury profiles in the different sports it is recommended that sports specific preventive measures should be employed to decrease the number of violent contacts between athletes, including improved game rules supported by careful refereeing. To prevent dental injuries the wearing of mouth guards should be encouraged, especially in ice hockey, karate, and basketball (Kujala, Taimela, Antti-Poika, Orava, Tuominen \& Myllynen, 1995).

Two experiments were conducted to investigate the reaction times (RTs) and anticipation of karate athletes. In Experiment 1, choice RTs and simple RTs were measured with two types of stimuli. One was videotaped scenes of opponent's offensive actions, which simulated the athletes' view in real situations, and the other was static filled circles, or dots. In the choice RT task, participants were required to indicate as soon as possible whether the offensive actions would be aimed at the upper or middle level of their body, or the dot was presented either at a higher or a lower position. In the simple RT task, they were required to respond as soon as possible when the offensive action started from a static display of the opponent's ready stance, or a dot appeared on the 
display. The results showed significant differences between the karate athletes and the novices in the choice RT task, the difference being more marked for the video stimuli than for the dot stimuli. There was no significant difference in simple RT between the two groups of participants, for either type of stimuli. In Experiment 2, the proportions of correct responses (PCRs) were measured for video stimuli which were cut off at the seventh frame from the onset of the opponent's offensive action. The athletes yielded significantly higher PCRs than the novices. Collectively the results of the two experiments demonstrate the superior anticipatory skills of karate athletes regarding the target area of an opponent's attack (Mori, Ohtani \& Imanaka, 2002).

In another study, it examined whether each exercise and an entire karate training session can achieve: 1) accepted training intensity thresholds for effective aerobic capacity training, 2) energy expenditure (EE) thresholds for total body mass and fat weight loss, and 3) elevation in excess post-exercise oxygen consumption (EPOC). The researchers investigated physiological responses during five types of karate training: basic techniques without (S-Basics) and with (M-Basics) movements, sparring techniques without (TECH I) and with (TECH II) an opponent, and kata. Findings revealed that the mean percent of maximal oxygen uptake (\%VO2max) and HR (\%HRmax) for S-Basics were below the accepted threshold ( $60 \%$ of HRmax or $50 \%$ of VO2max) and for M-Basics, TECH I and TECH II were above the threshold for increasing VO2max. For kata and the entire 70 min of karate training, the mean \%HRmax were slightly above the threshold, and $\%$ VO2max were slightly below the threshold. The mean EPOC measured for 5 min immediately following 70 min of karate training did not differ from the resting VO2. The mean EE resulting from 70 min of karate exercise and EPOC were $2355.4+/-316.3 \mathrm{~kJ}$ and $38.8+/-32.7 \mathrm{~kJ}$, respectively. Although the training intensity of karate exercises studied was moderate and the effects of karate training on EPOC were minimal, the mean value of EE was well 
above the accepted threshold for total body mass and fat weight loss (Imamura, Yoshimura, Nishimura, Nakazawa, Nishimura \& Shirota, 1999).

Karate injuries sustained in three national and three international tournaments were reviewed. Two hundred and eightyfour athletes participated in 309 matches. Athletes had an average age of 25.5 years, average years of karate practice of 7.7 years, and average years of competitive experience in tournaments of 3.1 years. Athletes were mostly black belts with gradation from brown belt to fourth degree black belt. There were 82 injuries sustained by 76 athletes within 309 matches, with an incidence of one injury in every 3.7 matches or 0.3 injuries per match. There were more injuries among the lower ranked and less experienced athletes, indicating that injuries became less frequent with increased tournament experience. Punches caused more injuries than kicks. Only 16 of the 76 injured athletes were forced to discontinue competition; one athlete was admitted to the hospital for 1 week due to a cerebral concussion (Stricevic, Patel, Okazaki, \& Swain, 1983).

The effect of 6 months of twice weekly karate training on flexibility, balance, and strength was evaluated in 14 boys who perform karate as beginners (age $M=10.3 \pm 1.8$ ) and a group of the same age who had never been involved in martial arts $(n=10$; age $M=10.9 \pm 1.4$ ). All subjects were pretested and posttested on the following: flexibility of upper extremity (shoulder), hamstrings and quadriceps; strength, including handgrip strength and concentric flexion/extension of quadriceps; and balance, with eyes either open or closed. After 6 months, the tests were evaluated and compared by groups. The results showed the karate group made significant gains on quadriceps flexibility and balance with eyes closed. By improving flexibility, balance, and strength, karate improves three of the basic fitness components that are very 
important for preventing sport injuries in the growing years (Violan, Small, Zetaruk \& Micheli, 1997).

\section{Methods}

This study employed the descriptive quantitative design. The study was conducted among fifteen enrollees of the University of Cebu Lapu-Lapu and Mandaue Karate Program. A five-point likert scale instrument was used with three parts: basic karate form; basic kata; and basic kumite. The participants were evaluated for six months with the following performance ratings:

5 - Excellent

4 - Very Good

3 - Satisfactory

2 - Needs Improvement

1 - Poor

For the interpretation of the results, the following mean ranges were used:
4.20-5.00 - Excellent
3.40-4.19 - Very Good
2.60-3.39 - Satisfactory
1.80-2.59 - Needs Improvement
1.00-1.79 - Poor 


\section{Results and Discussion}

Table 1 shows the performance evaluation of the recipients. Based on the results of the Basic Karate Form, recipients were Very Good in 7 aspects. These includes close stance (3.6), natural stance (3.6), forward stance (3.4), lunge punch (3.6), reverse punch (3.4), downward block (3.6), and rising block (3.6). The basic kata and basic kumite techniques were rated as satisfactory. Overall, the basic karate form was rated as satisfactory.

Among the techniques of the basic karate form, the following had the lowest performance evaluation: knife hand block (2.6), round house kick (2.7), triple punch (2.8), side kick (2.8), and back stance (2.8).

In the basic kata techniques, the transitional movements (2.6), synchronization (2.6), and balance (2.6) were among the techniques with the lowest performance evaluation.

For basic kumite techniques, the vigorous application (2.8), awareness (2.8), good timing (2.8), and correct distance (2.8) were among the techniques with the lowest performance evaluation.

\section{Table 1. Basic Karate Form}

\begin{tabular}{|l|c|c|}
\hline Basic Techniques & Mean & Interpretation \\
\hline Close Stance & 3.6 & Very Good \\
\hline Natural Stance & 3.6 & Very Good \\
\hline Forward Stance & 3.4 & Very Good \\
\hline Back Stance & 2.8 & Satisfactory \\
\hline Straddle Leg Stance & 3.0 & Satisfactory \\
\hline Lunge Punch & 3.6 & Very Good \\
\hline Reverse Punch & 3.4 & Very Good \\
\hline Straight Punch & 3.3 & Satisfactory \\
\hline
\end{tabular}




\begin{tabular}{|l|c|c|}
\hline Double Punch & 3.2 & Satisfactory \\
\hline Triple Punch & 2.8 & Satisfactory \\
\hline Downward Block & 3.6 & Very Good \\
\hline Rising Block & 3.6 & Very Good \\
\hline Outside Block & 3.2 & Satisfactory \\
\hline Inside Block & 3.2 & Satisfactory \\
\hline Knife Hand Block & 2.6 & Satisfactory \\
\hline Front Kick & 3.1 & Satisfactory \\
\hline Round House Kick & 2.7 & Satisfactory \\
\hline Side Kick & 2.8 & Satisfactory \\
\hline Grand Mean & 3.2 & Satisfactory \\
\hline
\end{tabular}


Table 2. Basic Kata

\begin{tabular}{|l|c|c|}
\hline Basic Techniques & Mean & Interpretation \\
\hline $\begin{array}{l}\text { Conformance to the form } \\
\text { and the standards required } \\
\text { on the level of the Kata } \\
\text { performed }\end{array}$ & 2.8 & Satisfactory \\
\hline Stances & & \\
\hline Techniques & 3.3 & Satisfactory \\
\hline Transitional movements & 2.9 & Satisfactory \\
\hline Synchronisation & 2.6 & Satisfactory \\
\hline Timing & 2.6 & Satisfactory \\
\hline Correct Breathing & 2.7 & Satisfactory \\
\hline Focus & 2.8 & Satisfactory \\
\hline Strength & 3.2 & Satisfactory \\
\hline Speed & 2.8 & Satisfactory \\
\hline Balance & 2.8 & Satisfactory \\
\hline Rhythm & 2.6 & Satisfactory \\
\hline Grand Mean & 2.6 & Satisfactory \\
\hline
\end{tabular}

\section{Table 3. Basic Kumite}

\begin{tabular}{|l|c|c|}
\hline Basic Techniques & Mean & Interpretation \\
\hline Good Form & 3.0 & Satisfactory \\
\hline Sporting Attitude & 2.9 & Satisfactory \\
\hline Vigorous Application & 2.8 & Satisfactory \\
\hline Awareness & 2.8 & Satisfactory \\
\hline Good Timing & 2.8 & Satisfactory \\
\hline Correct Distance & 2.8 & Satisfactory \\
\hline Grand Mean & 2.85 & Satisfactory \\
\hline
\end{tabular}


Table 4. Summary of Performance Evaluation

\begin{tabular}{|l|c|c|}
\hline Basic Techniques & Mean & Interpretation \\
\hline Basic Karate Form & 3.2 & Satisfactory \\
\hline Basic Kata Form & 2.8 & Satisfactory \\
\hline Basic Kumite Form & 2.85 & Satisfactory \\
\hline Grand Mean & 2.95 & Satisfactory \\
\hline
\end{tabular}

\section{Conclusion}

As an art to foster self-discipline and reliance, and one of the community extension programs of the college, the researchers concluded that there is a need to improve the skills performance of the recipients. This gap may be addressed by reinforcing lessons on basic techniques with the lowest performance evaluation. The researchers recommend the awarding of belts and conduct of tournaments to enhance competitiveness.

\section{Literature Cited}

Amparado, M. A. P., Camayra, M. T., Dorio Jr., P. A. \& Patindol, D. B. (2017). Sustainable Community Extension Programs for Village Looc, Mandaue City, Cebu, Philippines: The $8^{\text {th }}$ year Re-assessment. IAMURE International Journal of Social Sciences, 19(1), 102-114.

Amparado, M. A. P. \& Colonia, G. E. (2020). Community Needs Assessment of Village Opao, Mandaue City, Cebu, Philippines. Cebu Journal of Teacher Education, 1(1), 83100.

Kujala, U. M., Taimela, S., Antti-Poika, I., Orava, S., Tuominen, R., \& Myllynen, P. (1995). Acute injuries in soccer, ice hockey, volleyball, basketball, judo, and karate: analysis of national registry data. $B m j, 311(7018), 1465-1468$. 
Mori, S., Ohtani, Y., \& Imanaka, K. (2002). Reaction times and anticipatory skills of karate athletes. Human movement science, 21(2), 213-230.

Imamura, H., Yoshimura, Y., Nishimura, S., Nakazawa, A. T., Nishimura, C., \& Shirota, T. (1999). Oxygen uptake, heart rate, and blood lactate responses during and following karate training. Medicine and science in sports and exercise, 31(2), 342-347.

Stricevic, M. V., Patel, M. R., Okazaki, T., \& Swain, B. K. (1983).

Karate: historical perspective and injuries sustained in national and international tournament competitions. The American journal of sports medicine, 11(5), 320-324.

Violan, M. A., Small, E. W., Zetaruk, M. N., \& Micheli, L. J. (1997). The effect of karate training on flexibility, muscle strength, and balance in 8-to 13-year-old boys. Pediatric Exercise Science, $9(1), 55-64$.

http://www.tulane.edu/ karate/karate.htm, Retrieved on December 15, 2017.

\section{http://www.sandovalkarate.net/how-does-the-belt-system-in-}

karate-work/, Retrieved on December 15, 2017. 